\title{
HLA-A*020 I-restricted CTL epitope of a novel osteosarcoma antigen, papillomavirus binding factor
} Tomohide Tsukahara ${ }^{1,2}$, Satoshi Kawaguchi*1, Toshihiko Torigoe ${ }^{2}$, Akari Takahashi' ${ }^{2}$, Masaki Murase ${ }^{1,2}$, Masanobu Kano ${ }^{1,2}$, Takuro Wada ${ }^{1}$, Mitsunori Kaya ${ }^{1}$, Satoshi Nagoya ${ }^{1}$, Toshihiko Yamashita ${ }^{1}$ and Noriyuki Sato ${ }^{2}$

Address: ${ }^{1}$ Department of Orthopaedic Surgery, Sapporo Medical University School of Medicine, South-1, West-16, Chuo-ku, Sapporo, 060-8543, Japan and 2Department of Pathology, Sapporo Medical University School of Medicine, South-1, West-17, Chuo-ku, Sapporo, 060-8556, Japan

Email: Tomohide Tsukahara - tukahara@sapmed.ac.jp; Satoshi Kawaguchi* - kawaguch@sapmed.ac.jp;

Toshihiko Torigoe - torigoe@sapmed.ac.jp; Akari Takahashi - atakahashi@sapporo.jst-plaza.jp; Masaki Murase - murasem@sapmed.ac.jp; Masanobu Kano - kanomasa@sapmed.ac.jp; Takuro Wada - twada@sapmed.ac.jp; Mitsunori Kaya - mkaya@sapmed.ac.jp;

Satoshi Nagoya - nagoya@sapmed.ac.jp; Toshihiko Yamashita - tyamasit@sapmed.ac.jp; Noriyuki Sato - nsatou@sapmed.ac.jp

* Corresponding author

Published: 12 June 2009

Journal of Translational Medicine 2009, 7:44 doi:10.1 186/1479-5876-7-44
Received: I June 2009

Accepted: 12 June 2009

This article is available from: http://www.translational-medicine.com/content/7///44

(C) 2009 Tsukahara et al; licensee BioMed Central Ltd.

This is an Open Access article distributed under the terms of the Creative Commons Attribution License (http://creativecommons.org/licenses/by/2.0), which permits unrestricted use, distribution, and reproduction in any medium, provided the original work is properly cited.

\begin{abstract}
Background: To develop peptide-based immunotherapy for osteosarcoma, we previously identified papillomavirus binding factor (PBF) as a CTL-defined osteosarcoma antigen in the context of HLA-B55. However, clinical application of PBF-based immunotherapy requires identification of naturally presented CTL epitopes in osteosarcoma cells in the context of more common HLA molecules such as HLA-A2.
\end{abstract}

Methods: Ten peptides with the HLA-A*020I binding motif were synthesized from the amino acid sequence of PBF according to the BIMAS score and screened with an HLA class I stabilization assay. The frequency of CTLs recognizing the selected PBF-derived peptide was determined in peripheral blood of five $\mathrm{HLA}-\mathrm{A}^{*} \mathrm{O20 \textrm {I } ^ { + }}$ patients with osteosarcoma using limiting dilution (LD)/mixed lymphocyte peptide culture (MLPC) followed by tetramer-based frequency analysis. Attempts were made to establish PBF-specific CTL clones from the tetramer-positive CTL pool by a combination of limiting dilution and single-cell sorting. The cytotoxicity of CTLs was assessed by ${ }^{51} \mathrm{Cr}$ release assay.

Results: Peptide PBF A2.2 showed the highest affinity to HLA-A*020I. CD8+ T cells reacting with the PBF A2.2 peptide were detected in three of five patients at frequencies from $2 \times 10^{-7}$ to $5 \times 10^{-}$ 6. A tetramer-positive PBF A2.2-specific CTL line, 5A9, specifically lysed allogeneic osteosarcoma cell lines that expressed both PBF and either HLA-A*020I or HLA-A*0206, autologous tumor cells, and T2 pulsed with PBF A2.2. Five of 12 tetramer-positive CTL clones also lysed allogeneic osteosarcoma cell lines expressing both PBF and either HLA-A*020I or HLA-A*0206 and T2 pulsed with PBF A2.2.

Conclusion: These findings indicate that PBF A2.2 serves as a CTL epitope on osteosarcoma cells in the context of HLA-A*020I, and potentially, HLA-A*0206. This extends the availability of PBFderived therapeutic peptide vaccines for patients with osteosarcoma. 


\section{Background}

Osteosarcoma is the most common primary malignant tumor of bone. The survival rate of patients with osteosarcoma was under $20 \%$ before 1970 . The introduction of neoadjuvant chemotherapy, establishment of guidelines for adequate surgical margins, and development of postexcision reconstruction raised the five-year survival rate to $60-70 \%[1,2]$. These advances overshadowed the pioneering adjuvant immunotherapy trials using autologous tumor vaccines for patients with osteosarcoma, despite their having some therapeutic efficacy [3-5]. However, the survival rate of patients with osteosarcoma has reached a plateau in the last decade $[6,7]$, which has reignited interest in immunotherapeutic approaches [8-10].

We previously identified papillomavirus-binding factor $(\mathrm{PBF})$ as a novel osteosarcoma antigen, using an osteosarcoma cell line and an autologous CTL (cytotoxic T lymphocyte) clone restricted by HLA-B*5502 [11,12]. PBF is a DNA-binding transcription factor and a regulator of apoptosis [13-15]. PBF protein is expressed in $92 \%$ of osteosarcomas. Moreover, PBF-positive sarcomas have a significantly worse prognosis than PBF-negative sarcomas $[16,17]$. Development of PBF-based immunotherapy requires identification of naturally presented CTL epitopes in osteosarcoma cells in the context of common HLA molecules such as HLA-A2 and HLA-A24. The present study was designed to determine HLA-A*0201restricted CTL epitopes from PBF.

\section{Methods}

This study was approved under institutional guidelines for the use of human subjects in research. The patients and their families as well as healthy donors gave informed consent for the use of blood samples and tissue specimens in our research.

\section{Cells}

The osteosarcoma cell lines OS2000 and KIKU were established in our laboratory $[11,18]$. The osteosarcoma cell lines U2OS, Saos-2 and HOS, human lymphoblastoid cell line T2, and erythroleukemia cell line K562 were purchased from ATCC (Manassas, VA). OS2000, KIKI, U2OS, Saos-2, HOS and K562 are PBF-positive [12]. U2OS, Saos2 , and T2 are HLA-A*0201 positive. The HLA genotypes of the osteosarcoma cell lines were as follows: OS2000, $A^{*} 2402, \quad B * 5502, \quad B^{*} 4002, C w^{*} 0102 ; \mathrm{U} 2 \mathrm{OS}, A^{*} 0201$, $A^{*} 3201, B^{*} 4402, C w^{*} 0501, C w^{*} 0704 ;$ Saos- $2, A^{*} 0201$, $A^{*} 2402, \quad B * 1302, \quad B * 4402, C w^{*} 0602, C w^{*} 0704 ;$ HOS, $A^{*} 0211 ， B^{*} 5201, C w^{*} 1202 ;$ KIKU, $A^{*} 0206, A^{*} 2402$, $B^{*} 4006, B^{*} 5201, C w^{*} 0802$ and $C w^{*} 1202$. Epstein-Barr virus-transformed $\mathrm{B}$ cell line NS-EBV-B was established from a healthy donor in our laboratory. Another EpsteinBarr virus-transformed B cell line, LCL-OS2000, was established from a patient with osteosarcoma [11].
Autologous tumor cells were developed from fresh frozen biopsy specimens of osteosarcoma. The specimens were thawed in Iscove's modified Dulbecco's modified Eagle's medium containing $10 \%$ FCS at room temperature, minced into small pieces and filtrated with a $70 \mu \mathrm{m}$ Cell Strainer (BD Biosciences, Bedford, MA). The cells were used immediately for cytotoxicity assay.

\section{Design and synthesis of PBF-derived peptides}

Based on the entire amino acid sequence of PBF, peptides with the ability to bind to HLA-A*0201 class I molecules were searched for through the World Wide Web site Bioinformatics and Molecular Analysis Section (BIMAS) HLA Peptide Binding Predictions http://wwwbimas.cit.nih.gov/molbio/hla bind/[19]. Based on the binding scores, ten peptides were selected and synthesized [see Additional file 1].

\section{HLA class I stabilization assay}

The affinity of peptides for HLA-A*0201 molecules was evaluated by T2 cell surface HLA class-I stabilization assay as described previously $[20,21]$. An HLA-A*0201-binding influenza matrix protein-derived peptide (Inf-MP A2; GILGFVFTL) [22] was used for positive control. Mouse H2Kb-restricted peptide VSV8 (RGYVYQGL) [23] was used for negative control. Assays were performed in triplicate. The affinity of each peptide for HLA-A*0201 molecules was evaluated by the percent mean fluorescence intensity (\%MFI) increase of the HLA-A*0201 molecules detected by staining with an anti-HLA-A2 monoclonal antibody (BB7.2, purchased from ATCC) using the following calculation. \%MFI increase: [(MFI with the given peptide - MFI without peptide)/(MFI without peptide)] $\times 100$.

\section{Limiting dilution/mixed lymphocyte peptide culture}

Prior to frequency analysis and cytotoxicity assays, PBMC of patients were subjected to mixed lymphocyte peptide culture under limiting dilution conditions (LD/MLPC) according to the method described by Karanikas et al. [24] with some modifications [17]. LD/MLPC aims to seed at most one CTL precursor cell per well and induces proliferation of the precursor cell by subsequent mixed lymphocyte peptide culture. For this purpose, the appropriate number of PBMC and $\mathrm{CD}^{+}$cells per well is considered to be $1 \times 10^{5}-2 \times 10^{5}[17,24]$.

PBMCs were used as a source of responder cells in the initial five subjects (Patients 1 and 2 and three healthy donors) and $\mathrm{CD}^{+}$cells were used in the following three patients (Patients 3-5) [see Additional file 2].

PBMC obtained from peripheral blood samples $(50 \mathrm{ml})$ of Patients 1 and 2 and three healthy donors were suspended in AIM-V (Invitrogen Corp., Carlsbad, CA) supplemented with $1 \%$ human serum (HS). These cells were 
incubated for $60 \mathrm{~min}$ at room temperature with peptide PBF A2.2 $(50 \mu \mathrm{g} / \mathrm{ml})$. Peptide-pulsed PBMC were seeded at $2 \times 10^{5}$ cells/200 $\mu \mathrm{l} /$ well into round-bottom 96-microwell plates in AIM-V with $10 \% \mathrm{HS}$, IL-2 $(20 \mathrm{U} / \mathrm{ml}$; a kind gift from Takeda Chemical Industries, Ltd., Osaka Japan) and IL-7 (10 ng/ml; R\&D Systems, Minneapolis, Minnesota, USA), and incubated. On day 7, half of the medium was replaced with fresh AIM-V containing IL-2, IL-7 and the same peptides. The cell cultures were maintained by adding fresh AIM-V containing IL-2. On days 14-21, they were subjected to tetramer-based frequency analysis.

PBMC obtained from Patients 3-5 were separated into $\mathrm{CD}^{+}$cells and $\mathrm{CD} 88^{-}$cells using magnetic anti-CD8 microbeads (Miltenyi Biotec, Gladbach, Germany). CD8cells were pulsed with the PBF A2.2 peptide for $60 \mathrm{~min}$. Half of the CD8 cells were cryopreserved at $-80^{\circ} \mathrm{C}$ for the second stimulation. CD8 ${ }^{+}$cells $\left(1.0-2.1 \times 10^{5} /\right.$ well $)$ and irradiated PBF A2.2 peptide-pulsed CD8- cells (1-5 × 105/ well) were cocultured in 48-well cell culture plates in 500 $\mu \mathrm{l}$ of AIM-V with $10 \% \mathrm{HS}$, IL-2 and IL-7. On day 7 , the second stimulation was performed by adding irradiated peptide-pulsed CD8- cells to each culture well in $500 \mu \mathrm{l}$ of AIM-V with $10 \%$ HS, IL-2 and IL-7. On days 13-23, they were subjected to tetramer-based frequency analysis.

\section{Tetramer-based frequency analysis}

An FITC-conjugated HLA-A*0201/HIV tetramer (here termed the control tetramer) and a PE-conjugated HLAA*0201/PBF A2.2 tetramer (A2/PBF A2.2 tetramer) were constructed by Medical \& Biological Laboratories Co., Ltd. (Tokyo, Japan). PBMCs from patients were stimulated with the PBF A2.2 peptide by using the LD/MLPC procedure as described above. From each microwell containing $200 \mu \mathrm{l}$ of the microculture pool, $100 \mu \mathrm{l}$ was transferred to a V-bottom microwell and washed. To the spin-down pellets, the control tetramer and A2/PBF A2.2 tetramer (10 $\mathrm{nM}$ in $25 \mu \mathrm{l}$ of PBS) were added in combination and incubated for $15 \mathrm{~min}$ at room temperature. Then a PE-Cy5conjugated anti-CD8 antibody (eBioscience, San Diego, California, USA) was added (dilution of 1:30 in $25 \mu \mathrm{l}$ of PBS containing the control tetramer and A2/PBF A2.2 tetramer) and incubated for another $15 \mathrm{~min}$. The cells were washed in PBS twice, fixed with $0.5 \%$ formaldehyde, and analyzed by flow cytometry using FACScan and CellQuest software (Becton Dickinson, San Jose, California, USA). CD8 $8^{+}$living cells were gated and the cells labeled with the A2/PBF A2.2 tetramer were referred to as tetramer-positive cells. Tetramer-positive cells in each well are theoretically derived from a single CTL precursor, regardless of the number (percentage) of tetramer-positive cells. Accordingly, the number of tetramer-positive wells represents the number of CTL precursors. The frequency of anti-PBF A2.2 CTLs was evaluated using the following calculation: (number of tetramer-positive wells)/ [(total number of tested wells) $\times$ (initial number of CD8+ cells per well)].

\section{Development of CTL line and CTL clones}

Attempts to establish CTL clones were made by a limiting dilution procedure and subsequent single-cell sorting procedures.

In the limiting dilution procedure, cells from a tetramerpositive $T$ cell pool derived from Patient 4 were replated into a 96-well round-bottom microplate at one cell per well. In each well, a T cell was cocultured with irradiated $\mathrm{A}^{*} 0201^{+}$NS-EBV-B cells $\left(2 \times 10^{4}\right)$ pulsed with the PBF A2.2 peptide and irradiated allogeneic PBMCs $\left(8 \times 10^{4}\right)$ in $200 \mu \mathrm{l}$ of AIM-V containing $10 \% \mathrm{HS}$, IL-2 $(200 \mathrm{U} / \mathrm{ml})$ and IL-7 $(10 \mathrm{ng} / \mathrm{ml})$. On days 7, 14 and 21 , the stimulation was repeated by adding irradiated peptide-pulsed NS-EBV cells $\left(1 \times 10^{4}\right)$, LCL-OS2000 cells $\left(1 \times 10^{4}\right)$, and allogeneic PBMCs $\left(8 \times 10^{4}\right)$ to each culture well in $100 \mu \mathrm{l}$ of freshly replaced AIM-V with $10 \%$ HS, IL-2 and IL-7. On day 35 , tetramer staining of all wells was performed. The tetramerpositive population was selected and further expanded. These cells were seeded at $2 \times 10^{3}$ per well with irradiated allogeneic PBMCs $\left(1 \times 10^{5}\right)$ in $100 \mu$ l of AIM-V containing $10 \%$ HS, IL-2 $(200 \mathrm{U} / \mathrm{ml})$ and phytohemagglutinin-P (PHA; $7.5 \mu \mathrm{g} / \mathrm{ml}$, Wako Chemicals, Osaka, Japan) in a total of 192 wells of 96-well round-bottom microplates. On day 7, $100 \mu \mathrm{l}$ of AIM-V containing 10\% HS and IL-2 was added. On day 14, all proliferated cells were collected, washed and replaced with fresh AIM-V containing $10 \%$ HS and IL-2, followed by maintenance in a 48 -well microplate at $0.5-1 \times 10^{6}$ cells per well. The established oligoclonal cell line was designated CTL 5A9.

Subsequently, a frozen stock of the oligoclonal CTL 5A9 was reactivated and subjected to single-cell sorting. In the reactivation procedure, thawed CTL 5A9 cells were cultured with allogeneic PBMCs in AIM-V containing 10\% HS, IL-2 $(200 \mathrm{U} / \mathrm{ml})$ and PHA $(7.5 \mu \mathrm{g} / \mathrm{ml})$ for 27 days. The reactivated CTL $5 \mathrm{~A} 9$ cells were stained by the A2/PBF A2.2 tetramer and the control tetramer. The tetramer-positive cells $(0.82 \%)$ were sorted at one cell per well using FACS Aria II (Becton Dickinson) with allogeneic PBMCs $\left(1 \times 10^{5}\right)$ to each culture well in $200 \mu$ l of AIM-V with $10 \%$ HS, IL-2 $(200 \mathrm{U} / \mathrm{ml})$ and PHA $(7.5 \mathrm{ug} / \mathrm{ml})$ in a total of 384 wells of 96-well microplates. On days 7, 10 and 14, half of each medium was replaced with fresh medium without PHA. On days 20-34, tetramer staining was performed. Single-cell sorting was repeated until tetramer staining showed single clone populations.

\section{Cytotoxicity assay}

CTL-mediated cytolytic activity was measured by a $6 \mathrm{~h}-$ ${ }^{51} \mathrm{Cr}$-release assay [25]. Osteosarcoma cell lines (U2OS, OS2000, Saos-2, KIKU and HOS), K562, T2, and autolo- 
gous osteosarcoma cells obtained from Patient 4 were used as target cells. T2 cells were treated with or without peptides at the indicated concentrations for $1 \mathrm{~h}$ at room temperature after ${ }^{51} \mathrm{Cr}$-labeling. An HIV peptide (SLYNTVATL)[26] was used as a negative control peptide. Target cells were labeled with $100 \mu \mathrm{Ci}$ of ${ }^{51} \mathrm{Cr}$ for $1 \mathrm{~h}$ at $37^{\circ} \mathrm{C}$. The labeled target cells were suspended in RPMI without serum and seeded to microwells $\left(2-5 \times 10^{3}\right.$ cells/well $)$.

CTL 5A9 and CTL clones were used as the effector cells. The effector cells were transferred to V-bottom microwells, suspended in AIM-V and mixed with the labeled target cells. After a $6 \mathrm{~h}$ incubation period at $37^{\circ} \mathrm{C}$, the ${ }^{51} \mathrm{Cr}$ level in the culture supernatant was measured using an automated gamma counter. The percentage of specific cytotoxicity was calculated as follows: the percentage of specific ${ }^{51} \mathrm{Cr}$ release $=100 \times($ experimental release - spontaneous release)/(maximum release - spontaneous release).

\section{Results}

Affinity of PBF-derived synthetic peptides to HLA-A*020I molecules

To determine HLA-A*0201-restricted epitopes of PBF, we synthesized 10 peptides from the amino acid sequence of PBF in accordance with the BIMAS scores for HLA-A*0201 affinity [see Additional file 1]. Subsequently we evaluated the affinity of these peptides to HLA-A*0201 molecules by HLA class I-stabilization assay [see Additional file 1]. Peptide PBF A2.2 showed the highest \%MFI increase among the peptides. Peptide titration experiments (Fig. 1) revealed dose-dependent increases of \%MFI by PBF A2.2

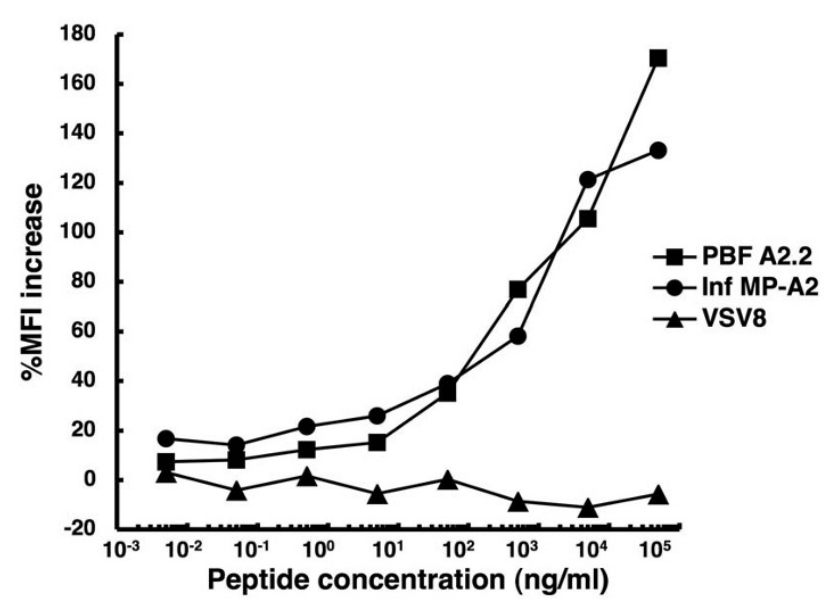

Figure I

Binding affinity of PBF A2.2 peptide to HLA-A*020 I molecules. The affinities of three peptides, PBF A2.2, Inf MP-A2 and VSV8, were determined by HLA class I stabilization assay at the indicated concentrations. and the positive control Inf-MP A2 peptide, but not the VSV8 negative control peptide.

Frequency of anti-PBF A2.2-specific T cells in HLA$A * 0201+$ patients with osteosarcoma and healthy donors We then examined the frequency of peripheral CD8+ Tlymphocytes that recognized the PBF A2.2 peptide in five HLA-A*0201+ patients with PBF-positive osteosarcoma by LD/MLPC/tetramer analysis. A2/PBF A2.2 tetramer-positive $\mathrm{T}$ cells were detected in three of the five patients [see Additional file 2]. Fig. 2 presents the results of flow cytometric analysis of Patient 4, showing two tetramer-positive wells and 12 of 34 tetramer-negative wells. This indicated the presence of at least two CTL precursor cells (PBF A2.2-specific CD8+ T cells) in $5.4 \times 10^{6} \mathrm{CD} 8+\mathrm{T}$ cells examined. The frequencies of the PBF A2.2-specific CD8 ${ }^{+}$ T cells ranged from $2 \times 10^{-7}$ to $5 \times 10^{-6}\left(2 \times 10^{-6}\right.$ on average) in three tetramer-positive patients. In the three healthy donors, the PBF A2.2-specific $\mathrm{CD} 8^{+} \mathrm{T}$ cells ranged from $1 \times 10^{-7}$ to $3 \times 10^{-7}\left(2 \times 10^{-7}\right.$ on average $)$.

\section{Establishment of A2/PBF A2.2 tetramer-positive CTL oligoclonal line and CTL clones}

Attempts to establish CTL clones were made by a combination of limiting dilution and repeated single-cell sorting. Limiting dilution of one of the tetramer-positive T cell pools from Patient 4 yielded a cell population (designated CTL 5A9) with more than $80 \%$ tetramer-positive CD ${ }^{+}$ cells (Fig. 3). RT-PCR analysis of TCR expression in CTL 5A9 revealed four $V$ alpha mRNAs (V alpha 3, 5, 8 and 12) and clonal $\mathrm{V}$ beta mRNA (V beta 13.1) (data not shown), indicating the oligoclonal nature of CTL 5A9.

We then performed single cell sorting of CTL 5A9 (Fig. 3). The first single-cell sorting resulted in 11 tetramer-positive oligoclonal populations. Two of these 11 oligoclones were subsequently subjected to the second single cell sorting. From one oligoclone (clone 140), 12 single clones were established. Of these, five clones (1B1, 1D7, 1E1, 1F4 and 1F7) showed cytotoxic activity to PBF A2.2pulsed T2 cells.

\section{Cytotoxicity of A2IPBF A2.2 tetramer-positive CTL oligoclonal line and CTL clones}

Finally we examined the cytotoxic properties of the oligoclonal line, 5A9, and five CTL clones. As shown in Fig. 4A, CTL 5A9 lysed PBF A2.2 peptide-pulsed T2 cells in an effector:target ratio-dependent manner. In contrast, such cytotoxic activity of CTL 5A9 was not seen against T2 cells without peptide pulsation or K562 cells. Cytotoxic activity of CTL 5A9 against PBF A2.2-pulsed T2 cells was dependent on the concentration of the PBF A2.2 peptide (Fig. $4 \mathrm{~B})$. Given the oligoclonal nature of CTL 5A9, we also examined the peptide-specific cytotoxicity of their tetramer-negative subpopulation. The tetramer-negative 


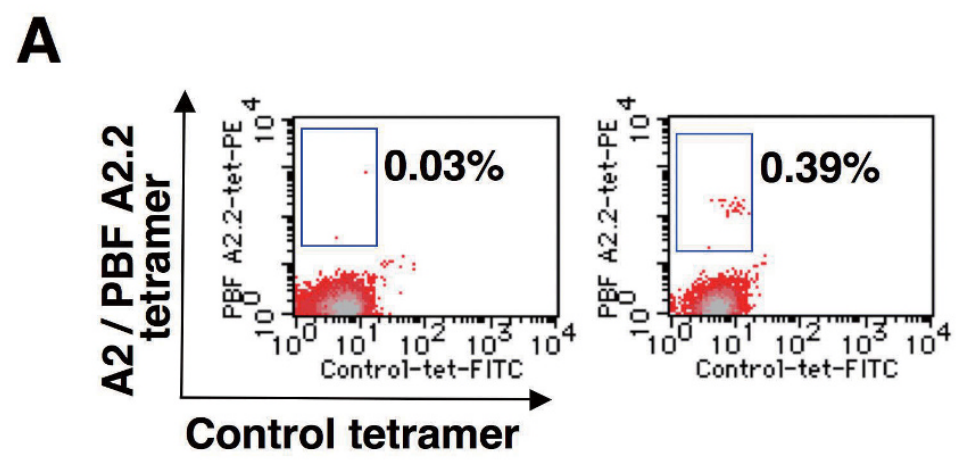

B
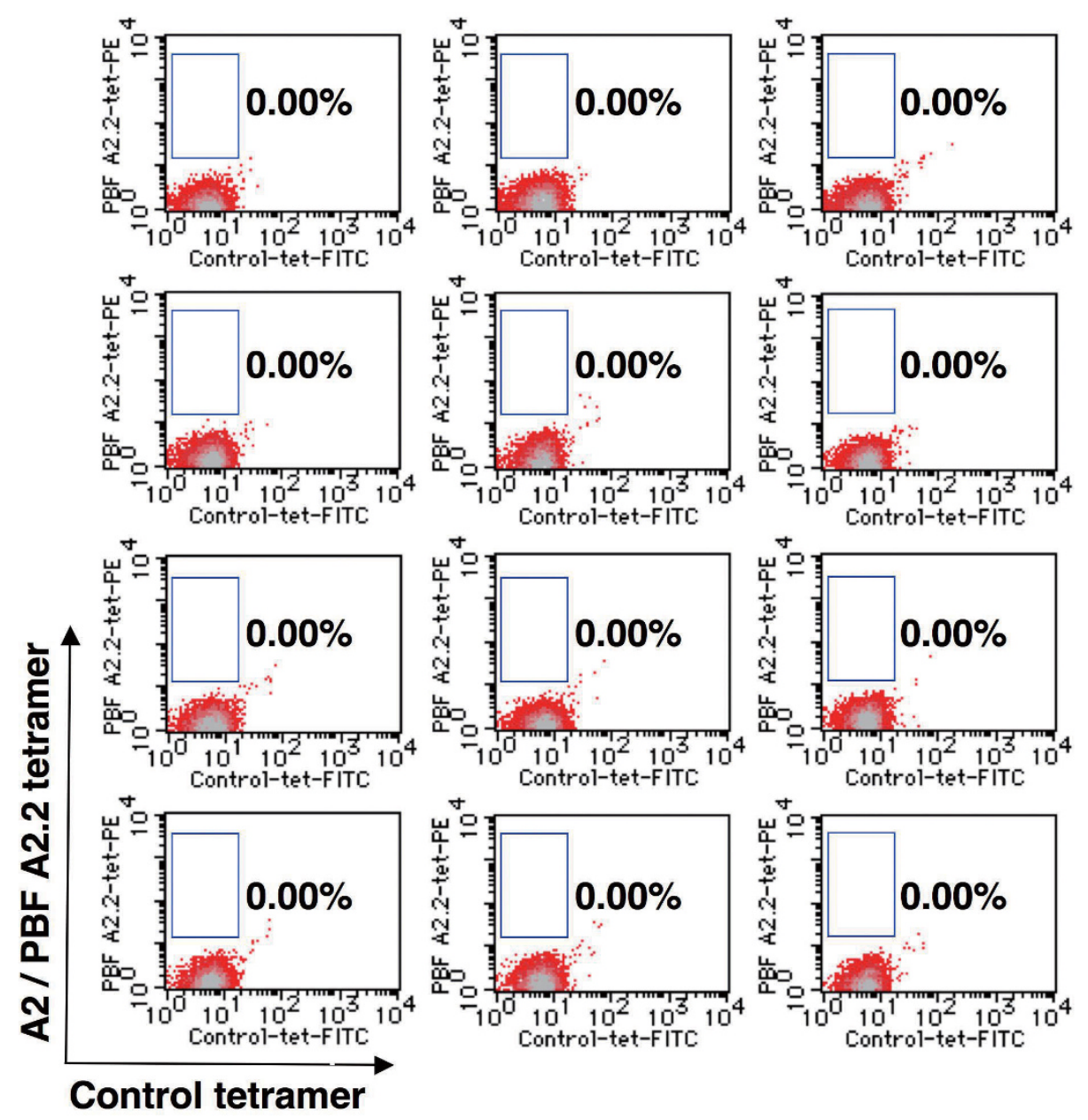

Figure 2

Tetramer-based detection of PBF A2.2-specific T cells. CD8+ T cells $\left(5.4 \times 10^{6}\right)$ collected from Patient 4 were seeded into 36 wells at the concentration of $\mathrm{I} .5 \times 10^{5}$ per well and cultured with peptide PBF A2.2 and cytokines. On day 2I, tetramer analysis was performed. This analysis showed that 2 of 36 wells were positive, containing $0.03 \%$ and $0.39 \%$ tetramer-positive cells, respectively (A). The remaining 34 wells were negative with $0.00 \%$ reactivity. Here, 12 of 34 tetramer-negative wells are shown (B). Each of the 2 positive wells contained at least I CTL precursor, indicating that there were at least 2 CTL precursors in a total of $5.4 \times 10^{6} \mathrm{CD} 8+$ cells. The frequency was calculated as $2 / 5.4 \times 10^{6}=3.7 \times 10^{-7}$. 


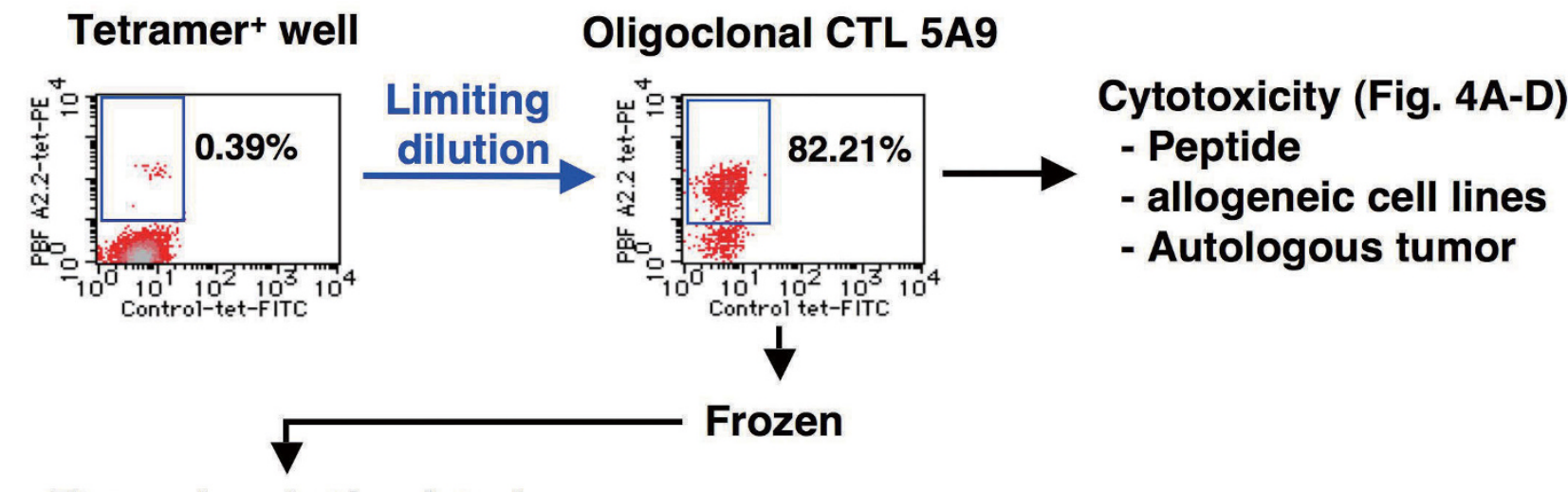

Thawed and stimulated
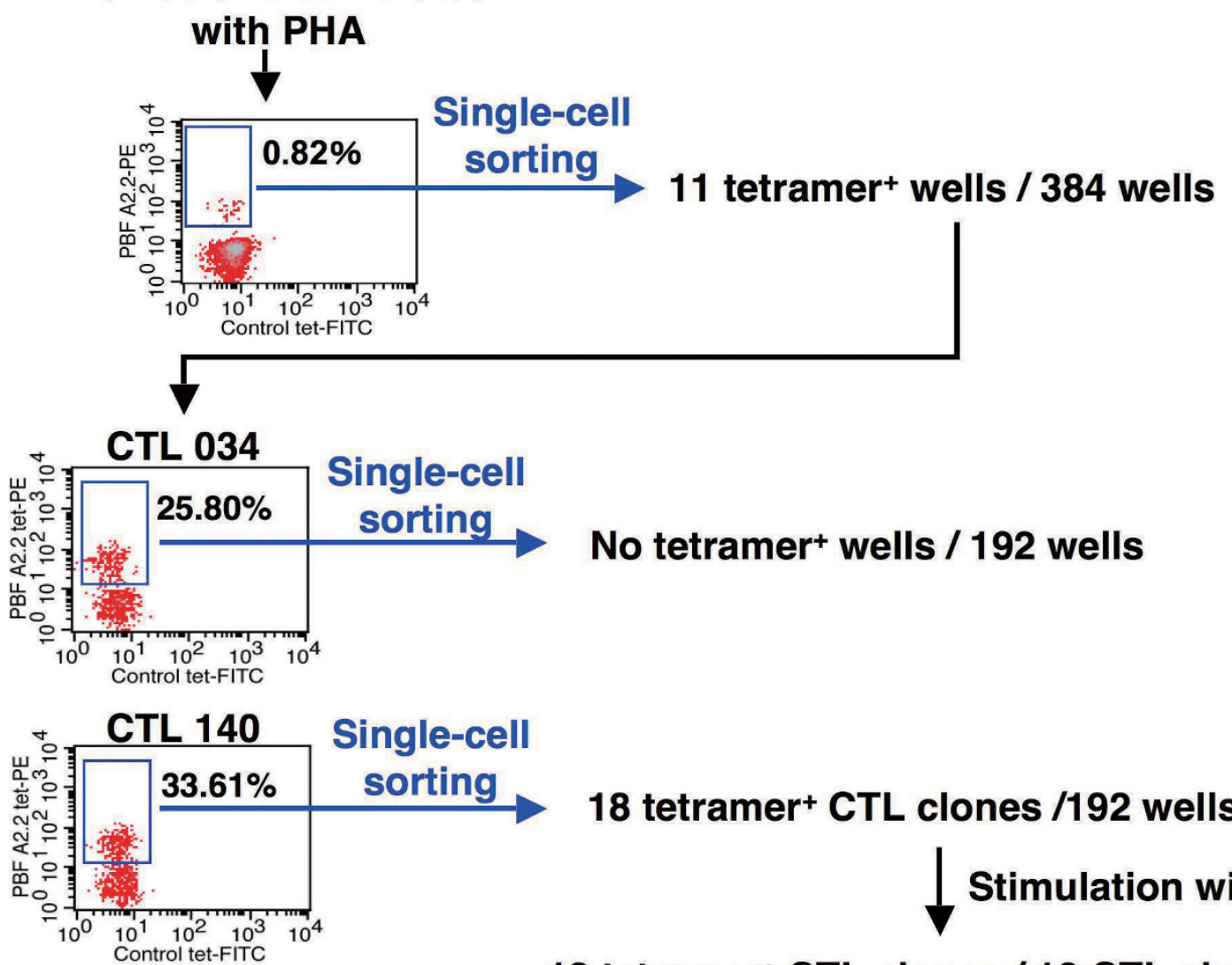

18 tetramer ${ }^{+}$CTL clones /192 wells Stimulation with PHA

12 tetramer ${ }^{+}$CTL clones / 18 CTL clones<smiles>CCCCCCCC</smiles>

5 tetramer+ CTL clones recognizing PBF A2.2

Cytotoxicity (Fig. 5)

- Peptide

- Allogeneic cell lines

Figure 3

Establishment of PBF A2.2-specific CTL line and CTL clones. 
A

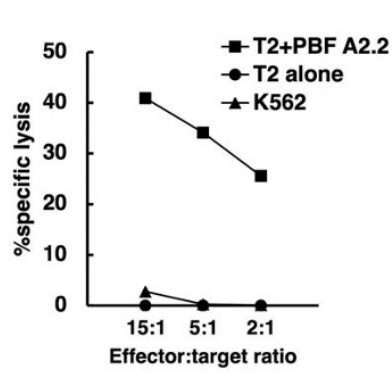

B
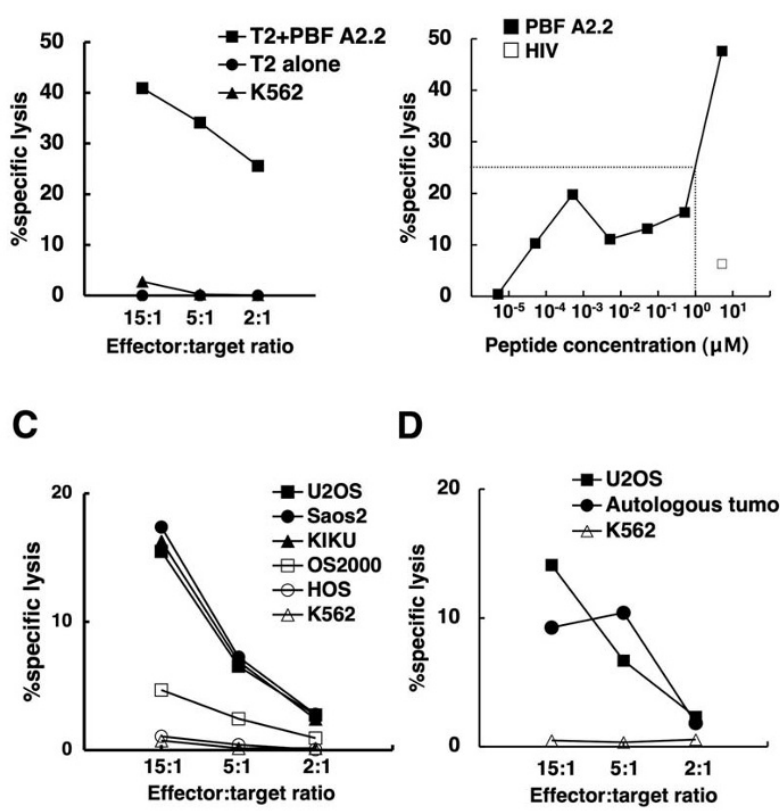

D

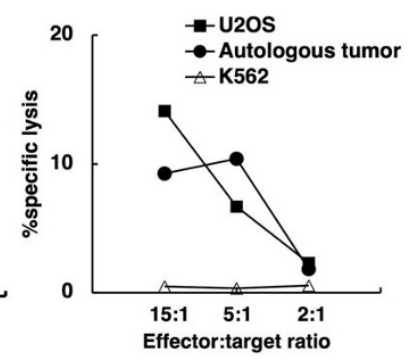

Figure 4

Cytotoxic activity of A2/PBF A2.2 tetramer-positive CTL line 5A9. A. The peptide-specific cytotoxicity of CTL $5 A 9$ was determined using $T 2$ and $K 562$ cells in a $6 \mathrm{~h}$ standard ${ }^{51} \mathrm{Cr}$ release assay. T2 cells were pulsed with $50 \mu \mathrm{g} / \mathrm{ml}$ peptide PBF A2.2 or medium for I h at room temperature after labeling with ${ }^{5} \mathrm{Cr}$. CTL 5A9 lysed PBF A2.2 peptidepulsed T2 cells in an effector:target ratio-dependent manner, but not K562 or T2 cells without peptide pulsation. B. T2 cells were incubated with various concentrations of the PBF A2.2 peptide and $5 \mu \mathrm{M}$ HIV control peptide. The cytotoxicity of CTL $5 A 9$ against peptide-pulsed T2 cells was determined at an effector to target ratio of 30:I. Dotted lines indicate half maximum lysis. C. The cytotoxicity of CTL 5A9 against allogeneic osteosarcoma cell lines U2OS, Saos-2, KIKU, OS2000 and HOS. All cell lines express PBF. U2OS and Saos2 are HLA-A*020I-positive. KIKU is HLA-A*020I-negative, HLA-A*0206-positive. OS2000 and HOS are HLA-A*020Inegative. D. Autologous tumor cells were derived from fresh-frozen biopsy specimens of Patient 4, from whom CTL $5 A 9$ was also developed. U2OS and $\mathrm{K} 562$ were used as positive control target cells and natural killer target cells, respectively.

5A9 subpopulation did not react against T2 cells, PBF A2.2 peptide-pulsed T2 cells, or K562 cells (data not shown).

Fig. 4C shows the cytotoxic activity of CTL 5A9 against osteosarcoma cells. CTL 5A9 exhibited cytotoxicity against U2OS (PBF-positive, HLA-A*0201-positive), Saos-2 (PBF- positive, HLA-A*0201-positive), and KIKU (PBF-positive, HLA-A*0201-negative, HLA-A*0206-positive) in an effector:target ratio-dependent manner. In contrast, CTL 5A9 showed marginal cytotoxicity against OS2000 (PBF-positive, HLA-A*0201-negative), and undetectable levels of cytotoxicity against HOS (PBF-positive, HLA-A*0201negative) and K562 cells (PBF-positive, HLA-null). To assess the possibility of an allogeneic reaction for the cytotoxicity of CTL 5A9, we developed autologous tumor cells from fresh-frozen biopsy specimens of Patient 4 and used them as target cells. As shown in Fig. 4D, CTL 5A9 also lysed autologous tumor cells as well as the positive control, U2OS cells, but not K562 cells.

To further determine the specificity of A2/PBF A2.2 tetramer-positive CTLs against osteosarcoma cells in the context of HLA-A2, we analyzed the cytotoxicity of five CTL clones derived from CTL 5A9 (Fig. 5). All five CTL clones lysed PBF A2.2 peptide-pulsed T2 cells and osteosarcoma cell lines U2OS and KIKU. In contrast, none of five clones recognized OS2000, HOS or K562.

\section{Discussion}

In the present study, we examined the immunogenicity of an HLA-A*0201-binding peptide derived from a novel tumor-associated antigen PBF. The peptide PBF A2.2 was recognized by $\mathrm{CD} 8+\mathrm{T}$ cells in three of five HLA-A*0201positive patients with osteosarcoma and induced an oligoclonal CTL line and five CTL clones from these CD8 ${ }^{+} \mathrm{T}$ cells. The CTL line, CTL 5A9, and five CTL clones all exhibited specific cytotoxic activity against PBF A2.2-pulsed T2 cells and allogeneic osteosarcoma cell lines expressing both HLA-A*0201 and PBF. In addition, CTL 5A9 lysed autologous osteosarcoma cells derived from fresh biopsy specimens. These findings indicated that PBF A2.2 served as a CTL epitope on osteosarcoma cells in the context of HLA-A*0201.

Interestingly, CTL 5A9 and the five CTL clones lysed an allogeneic osteosarcoma cell line (KIKU) that expressed PBF and HLA-A*0206, but not HLA-A*0201. This suggested that the peptide PBF A2.2 might also be presented on osteosarcoma cells in the context of HLA-A*0206, as seen for other tumor-associated antigens $[27,28]$. Alternatively, CTL 5A9 and the five CTL clones might cross-react with an allogeneic antigen presented by HLA-A*0206, $\mathrm{B}^{*} 4006$, or $-\mathrm{CW}^{*} 0802$, that was not shared by OS2000 and HOS, on KIKU cells. To determine these possibilities, cytotoxicity assays with other target cells that express both PBF and HLA-A*0206 will be required. Thus far, the proof of immunogenicity of PBF has been limited to an HLAB55-positive patient [12] and HLA-A24-positive patients with osteosarcoma [17]. Our findings in the present study 
1B1
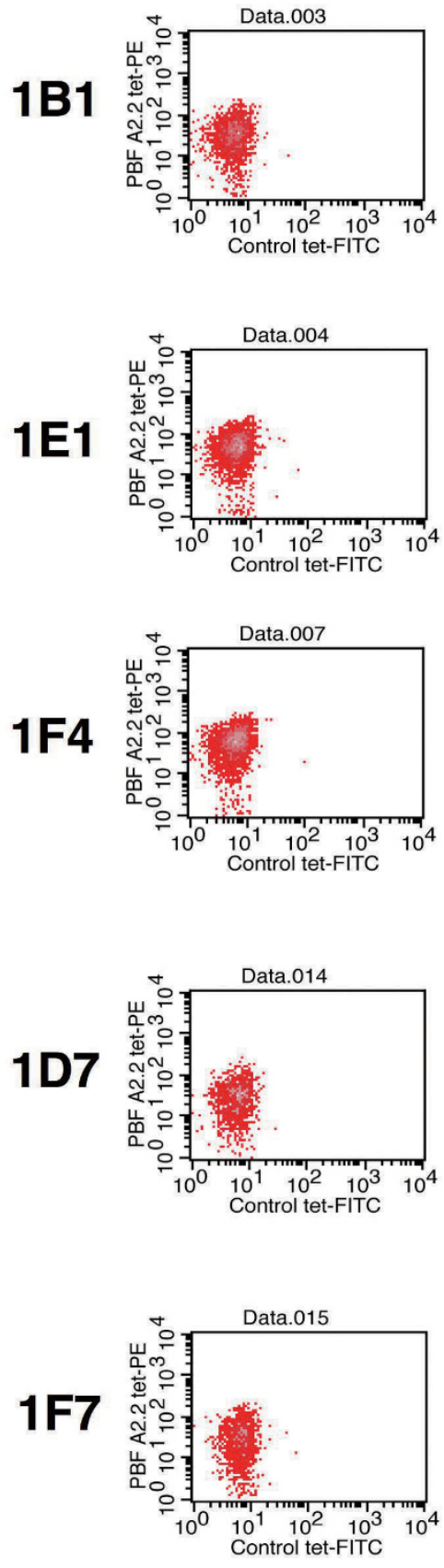
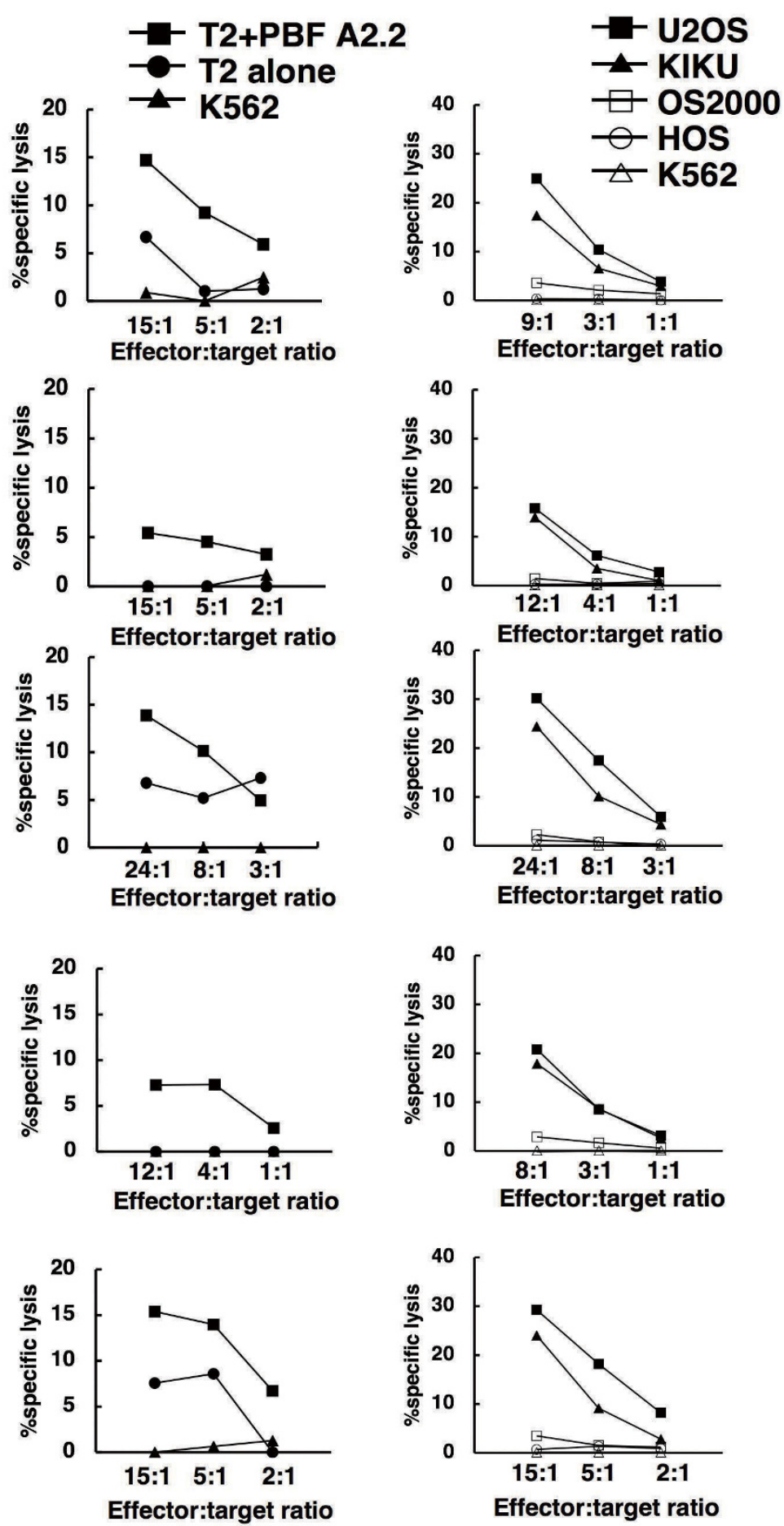

\section{Figure 5}

Cytotoxic activity of CTL clones derived from CTL 5A9. Five CTL clones were established from CTL 5A9. Left panels indicate tetramer staining of $C T L$ clones. $C D 8^{+}$cells were gated. $X$-axis and $Y$-axis indicate the fluorescence intensity of control tetramer-FITC and A2/PBF A2.2 tetramer-PE, respectively. Middle panels indicate CTL-mediated cytotoxicity against T2 cells with or without PBF A2.2 peptide-pulsation. Right panels indicate CTL-mediated cytotoxicity against allogeneic osteosarcoma cell lines. 
extend the application of PBF-targeting immunotherapy towards patients with HLA-A*0201 and potentially those with HLA-A*0206.

The frequency of the PBF A2.2-specific CTL precursors ranged from $2 \times 10^{-7}$ to $5 \times 10^{-6}$ in patients with osteosarcoma. On the other hand, the frequency of the PBF A2.2specific CTL precursors in healthy donors ranged from $1 \times$ $10^{-7}$ and $3 \times 10^{-7}$. In our previous study [17], the frequency of PBF A24.2-specific CTL precursors was between $5 \times 10^{-}$ 7 and $7 \times 10^{-6}$. In melanoma patients, the MAGE3.A1-specific CTL precursor frequency was less than $10^{-7}$ in normal individuals and non-vaccinated patients as determined by the LD/MLPC/tetramer procedure [29]. Notably the frequency of MAGE3.A1-specific CTL precursors rose to 10-6 following vaccination [29]. Therefore the significance of measuring the frequency of peptide-reactive CTL precursors is to determine the baseline frequency in non-vaccinated patients for forthcoming clinical vaccination trials.

The frequency of CTL precursors is generally under the detection limit of the standard tetramer analysis [30-33] so the $\mathrm{LD} / \mathrm{MLPC} /$ tetramer procedure was developed. The presence of false-positive wells is a concern in the $\mathrm{LD} /$ MLPC/tetramer procedure. To reduce this, we doublestained cells with A2/PBF A2.2 tetramer-PE and control tetramer-FITC (this detects cells that nonspecifically bind tetramers). In tetramer-positive wells, percentages of tetramer-positive cells varied from $0.03 \%$ to $0.39 \%$ in the present study. The variation of the percentages of tetramer-positive cells conceptually reflects the differing proliferation activities of a single CTL precursors seeded in each well, but does not affect calculation of the frequency of CTL precursors. Therefore, it is critical in the LD/MLPC/ tetramer procedure to detect cells that react with the A2/ PBF A2.2 tetramer despite the quite low percentages.

\section{Conclusion}

The present study demonstrates the immunogenicity of peptide PBF A2.2 in HLA-A*0201-positive patients with osteosarcoma. The PBF A2.2 peptide is a novel antigenic peptide naturally presented on osteosarcoma cells in the context of HLA-A*0201 and, potentially, HLA-A*0206. This extends the availability of PBF-derived therapeutic peptide vaccines for patients with osteosarcoma.

\section{Competing interests}

The authors declare that they have no competing interests.

\section{Authors' contributions}

TT designed the study, carried out most experiments and drafted the manuscript.

SK made a substantial contribution to critical reading. AT performed single-cell sorting. MM and MK participated in the preparation of patients' samples. SK, TW, MK and SN contributed to collecting patients' samples with the informed consent. SK, TT, TW, TY and NS participated in its design and coordination. All authors read and approved the final manuscript.

\section{Additional material}

\section{Additional file 1 \\ Sequences and binding affinities of PBF-derived peptides with HLA- $A * 0201$ binding motif. ${ }^{*}$ Binding score was determined by BIMAS HLA Peptide Binding Predictions. ${ }^{+}$The affinity of each peptide $(50 \mu \mathrm{g} / \mathrm{ml})$ was evaluated by a HLA class I stabilization assay. \\ Click here for file \\ [http://www.biomedcentral.com/content/supplementary/1479- \\ 5876-7-44-S1.xls]}

\section{Additional file 2}

Clinical picture and frequency of anti-PBF A2.2 peptide CTLs in PBMC of patients with osteosarcoma. P: primary tumor, M: metastatic tumor. ${ }^{\dagger}$ Frequency of anti-PBF A2.2 CTLs among CD8+ cells. ${ }^{\ddagger}$ Parentheses indicate that the tumor had been resected at the time of blood sampling. ${ }^{\circledR}$ Magnetically separated CD8+ cells. Irradiated peptide-pulsed CD8-cells were used as stimulator.

Click here for file

[http://www.biomedcentral.com/content/supplementary/14795876-7-44-S2.xls]

\section{Acknowledgements}

The authors thank Drs. Pierre G. Coulie (Christian de Duve Institute of Cellular Pathology, Université Catholique de Louvain, Brussels, Belgium) and Tomoko So (The Second Department of Surgery, University of Occupational and Environmental Health, Kitakyushu, Japan) for kind advice about the LD/MLPC/tetramer procedure, and Dr. Hideo Takasu (Division of Drug Research, Dainippon Sumitomo Pharma Co., Ltd., Osaka, Japan) for the kind donation of synthetic peptides. This work was supported by Grants-in-Aid from the Ministry of Education, Culture, Sports, Science and Technology of Japan (Grant No. 16209013 to N. Sato, No. 20390403 to T. Wada), Practical Application Research from the Japan Science and Technology Agency (Grant No. HI4-2 to N. Sato), the Ministry of Health, Labor and Welfare (Grant No. HI7-Gann-Rinsyo-006 to T. Wada), Postdoctoral Fellowship of the Japan Society for the Promotion of Science (Grant No. 02568 to T. Tsukahara), Northern Advancement Center for Science and Technology (Grant No. HI8-Waka-075 to T. Tsukahara), The Uehara Memorial Foundation (Grant No. HI9-Kenkyu-Syorei to T. Tsukahara), and Grant of Japan Orthopedics and Traumatology Foundation, Inc ( $\mathrm{H} 20-$ Kenkyu-Zyosei to T. Tsukahara).

\section{References}

I. Ferrari S, Palmerini E: Adjuvant and neoadjuvant combination chemotherapy for osteogenic sarcoma. Curr Opin Oncol 2007, 19:34I-346.

2. The JOA Musculo-Skeletal Tumor Committee: General rules for clinical and pathological studies on malignant bone tumors. 3rd edition. Tokyo: Kanabara; 2000.

3. Southam CM, Marcove RC, Levin AG, Buchsbaum HJ, Mike V: Proceedings: Clinical trial of autogenous tumor vaccine for treatment of osteogenic sarcoma. Proc Natl Cancer Conf 1972, 7:91-100. 
4. Campbell CJ, Cohen J, Enneking WF: Editorial: New therapies for osteogenic sarcoma. J Bone Joint Surg Am 1975, 57: I43-I 44.

5. Kawaguchi S, Wada T, Tsukahara T, Ida K, Torigoe T, Sato N, Yamashita $\mathrm{T}$ : A quest for therapeutic antigens in bone and soft tissue sarcoma. J Transl Med 2005, 3:31.

6. Lewis VO: What's new in musculoskeletal oncology. J Bone Joint Surg Am 2007, 89: I399-| 407.

7. Meyers PA, Schwartz CL, Krailo M, Kleinerman ES, Betcher D, Bernstein ML, Conrad E, Ferguson W, Gebhardt M, Goorin AM, et al.: Osteosarcoma: a randomized, prospective trial of the addition of ifosfamide and/or muramyl tripeptide to cisplatin, doxorubicin, and high-dose methotrexate. J Clin Oncol 2005, 23:2004-20II.

8. Maki RG: Future directions for immunotherapeutic intervention against sarcomas. Curr Opin Oncol 2006, 18:363-368.

9. Sato N, Hirohashi Y, Tsukahara T, Kikuchi T, Sahara H, Kamiguchi K, Ichimiya S, Tamura Y, Torigoe T: Molecular pathological approaches to human tumor immunology. Pathol Int 2009, 59:205-217.

10. Tsukahara T, Torigoe T, Tamura Y, Wada T, Kawaguchi S, Tsuruma T, Hirata K, Yamashita T, Sato N: Antigenic peptide vaccination: Provoking immune response and clinical benefit for cancer. Curr Immunol Rev 2008, 4:235-24I.

II. Nabeta Y, Kawaguchi S, Sahara H, lkeda H, Hirohashi Y, Goroku T, Sato Y, Tsukahara T, Torigoe T, Wada T, et al.: Recognition by cellular and humoral autologous immunity in a human osteosarcoma cell line. J Orthop Sci 2003, 8:554-559.

12. Tsukahara T, Nabeta $Y$, Kawaguchi S, Ikeda H, Sato Y, Shimozawa K, Ida K, Asanuma H, Hirohashi Y, Torigoe T, et al.: Identification of human autologous cytotoxic T-lymphocyte-defined osteosarcoma gene that encodes a transcriptional regulator, papillomavirus binding factor. Cancer Res 2004, 64:5442-5448.

13. Boeckle S, Pfister H, Steger G: A new cellular factor recognizes E2 binding sites of papillomaviruses which mediate transcriptional repression by E2. Virology 2002, 293:103-117.

14. Sichtig N, Silling S, Steger G: Papillomavirus binding factor (PBF)-mediated inhibition of cell growth is regulated by I43-3beta. Arch Biochem Biophys 2007, 464:90-99.

15. Tsukahara T, Kimura S, Ichimiya S, Torigoe T, Kawaguchi S, Wada T, Yamashita T, Sato N: Scythe/BAT3 regulates apoptotic cell death induced by papillomavirus binding factor in human osteosarcoma. Cancer Sci 2009, 100:47-53.

16. Yabe H, Tsukahara T, Kawaguchi S, Wada T, Sato N, Morioka H, Yabe $H$ : Overexpression of papillomavirus binding factor in Ewing's sarcoma family of tumors conferring poor prognosis. Oncol Rep 2008, 19:129-134.

17. Tsukahara T, Kawaguchi S, Torigoe T, Kimura S, Murase M, Ichimiya S, Wada T, Kaya M, Nagoya S, Ishii T, et al.: Prognostic impact and immunogenicity of a novel osteosarcoma antigen, papillomavirus binding factor, in patients with osteosarcoma. Cancer Sci 2008, 99:368-375.

18. Wada T, Uede T, Ishii S, Matsuyama K, Yamawaki S, Kikuchi K: Monoclonal antibodies that detect different antigenic determinants of the same human osteosarcoma-associated antigen. Cancer Res 1988, 48:2273-2279.

19. Parker KC, Bednarek MA, Coligan JE: Scheme for ranking potential HLA-A2 binding peptides based on independent binding of individual peptide side-chains. J Immunol 1994, I52:163-175.

20. Kuzushima K, Hayashi N, Kimura H, Tsurumi T: Efficient identification of HLA-A*2402-restricted cytomegalovirus-specific CD8(+) T-cell epitopes by a computer algorithm and an enzyme-linked immunospot assay. Blood 200I, 98: |872-|88|.

21. Ida K, Kawaguchi S, Sato Y, Tsukahara T, Nabeta Y, Sahara H, Ikeda $\mathrm{H}$, Torigoe T, Ichimiya S, Kamiguchi $\mathrm{K}$, et al.: Crisscross CTL induction by SYT-SSX junction peptide and its HLA-A*2402 anchor substitute. J Immunol 2004, I 73:| |436-I 443.

22. Morrison J, Elvin J, Latron F, Gotch F, Moots R, Strominger JL, McMichael A: Identification of the nonamer peptide from influenza A matrix protein and the role of pockets of HLA-A2 in its recognition by cytotoxic $\mathbf{T}$ Iymphocytes. Eur J Immunol 1992, 22:903-907.

23. Kurotaki T, Tamura Y, Ueda G, Oura J, Kutomi G, Hirohashi $Y$, Sahara $H$, Torigoe T, Hiratsuka $H$, Sunakawa $H$, et al:: Efficient cross-presentation by heat shock protein 90-peptide complex-loaded dendritic cells via an endosomal pathway. I Immunol 2007, 179:|803-18|3.
24. Karanikas V, Lurquin C, Colau D, van Baren N, De Smet C, Lethe B, Connerotte T, Corbiere V, Demoitie MA, Lienard D, et al.: Monoclonal anti-MAGE-3 CTL responses in melanoma patients displaying tumor regression after vaccination with a recombinant canarypox virus. J Immunol 2003, I 7 I:4898-4904

25. Sato $Y$, Nabeta $Y$, Tsukahara $T$, Hirohashi $Y$, Syunsui R, Maeda $A$ Sahara $\mathrm{H}$, lkeda $\mathrm{H}$, Torigoe $T$, Ichimiya $S$, et al:: Detection and induction of CTLs specific for SYT-SSX-derived peptides in HLA-A24(+) patients with synovial sarcoma. J Immunol 2002, 169:1611-1618.

26. Kan-Mitchell J, Bisikirska B, Wong-Staal F, Schaubert KL, Bajcz M, Bereta M: The HIV-I HLA-A2-SLYNTVATL is a help-independent CTL epitope. J Immunol 2004, I 72:5249-526I.

27. Imai N, Harashima N, Ito M, Miyagi $Y$, Harada M, Yamada A, Itoh K: Identification of Lck-derived peptides capable of inducing HLA-A2-restricted and tumor-specific CTLs in cancer patients with distant metastases. Int J Cancer 200I, 94:237-242.

28. Ito M, Shichijo S, Miyagi Y, Kobayashi T, Tsuda N, Yamada A, Saito N Itoh K: Identification of SART3-derived peptides capable of inducing HLA-A2-restricted and tumor-specific CTLs in cancer patients with different HLA-A2 subtypes. Int J Cancer 2000, 88:633-639.

29. Lurquin C, Lethe B, De Plaen E, Corbiere V, Theate I, van Baren N Coulie PG, Boon T: Contrasting frequencies of antitumor and anti-vaccine $T$ cells in metastases of a melanoma patient vaccinated with a MAGE tumor antigen. J Exp Med 2005, 20I:249-257.

30. Connerotte $T$, Van Pel A, Godelaine D, Tartour E, Schuler-Thurner B, Lucas S, Thielemans K, Schuler G, Coulie PG: Functions of AntiMAGE T-cells induced in melanoma patients under different vaccination modalities. Cancer Res 2008, 68:393I-3940.

3I. Coulie PG, Karanikas V, Colau D, Lurquin C, Landry C, Marchand M, Dorval T, Brichard V, Boon T: A monoclonal cytolytic T-lymphocyte response observed in a melanoma patient vaccinated with a tumor-specific antigenic peptide encoded by gene MAGE-3. Proc Natl Acad Sci USA 200 I, 98: I0290-I0295.

32. So T, Hanagiri T, Chapiro J, Colau D, Brasseur F, Yasumoto K, Boon T, Coulie PG: Lack of tumor recognition by cytolytic T lymphocyte clones recognizing peptide 195-203 encoded by gene MAGE-A3 and presented by HLA-A24 molecules. Cancer Immunol Immunother 2007, 56:259-269.

33. Karanikas V, Soukou F, Kalala F, Kerenidi T, Grammoustianou ES, Gourgoulianis $\mathrm{KI}$, Germenis AE: Baseline levels of CD8+ $\mathbf{T}$ cells against survivin and survivin-2B in the blood of lung cancer patients and cancer-free individuals. Clin Immunol 2008, 1 29:230-240.

\section{Publish with Bio Med Central and every scientist can read your work free of charge}

"BioMed Central will be the most significant development for disseminating the results of biomedical research in our lifetime. "

Sir Paul Nurse, Cancer Research UK

Your research papers will be:

- available free of charge to the entire biomedical community

- peer reviewed and published immediately upon acceptance

- cited in PubMed and archived on PubMed Central

- yours - you keep the copyright
BioMedcentral 